\title{
Atmospheric Ice Accretion on Non-Rotating Vertical Circular Cylinder
}

\author{
Muhammad S. Virk*, Umair N. Mughal, Geanette Polanco \\ Atmospheric Icing Research Team, Industrial Engineering department, Narvik University College, Norway \\ Email: msv@hin.no
}

Received 10 September 2015; accepted 15 October 2015; published 22 October 2015

\begin{abstract}
Study of atmospheric ice accretion on a non-rotating vertical circular cylindrical object was carried out at dry and wet ice conditions. Both numerical and experimental techniques were used during this study. 3D numerical study was carried out using computational fluid dynamics based approach, whereas experimental study was carried out at Cryospheric Environmental Simulator 'CES' in Shinjo, Japan. A good agreement was found between experimental and numerical results. The dimensions of the cylindrical object used to measure the atmospheric ice load on structures along this study, were selected as per the IS012494 standard. Results provide useful information about ice growth and intensity along circular cylindrical objects at different atmospheric temperatures. This research work also provides a useful base for further investigation of atmospheric ice accretion on structures particularly circular power network cables, \& tower masts installed in the cold regions.
\end{abstract}

\section{Keywords}

Atmospheric Ice, Circular Cylinder, Temperature, CFD, Experiment

\section{Introduction}

Human activities are increasingly extending in the cold regions of high north, where atmospheric icing will not only make human inconveniences, but can also affect the human activities \& safety, significantly. Atmospheric ice accretion occurs when freezing rain drops, snow particles or super cooled water droplets come into contact with the exposed surface [1]. The potential for damage to facilities as a result of atmospheric ice accretion is considerable. Llinca et al. [2] reported that large amplitude oscillations of ice covered cables at low frequencies is responsible for about one third of power line maintenance and operating cost. The largest ice loads ever recorded on a power line is $305 \mathrm{Kg} / \mathrm{m}$. This was recorded on a $22 \mathrm{kV}$ overhead line in Voss, Norway on April 18, 1961 [3]. Numerical study of atmospheric ice accretion on structures includes the computation of mass flux of icing particles as well as determination of the icing conditions [4]. This can be numerically simulated by means of integrated thermo-fluid dynamic models. Most developments in the numerical modeling of ice accretion has been focused on aerospace industry and very few improvements has been reported in the research field of on-

"Corresponding author. 
shore structural icing. The main differences between ice accretion on an onshore structure and an aircraft are; firstly aircraft icing takes place at high air speed and small water droplets, while icing on onshore structures occurs in the presence of relatively low air velocity and largely varying droplet sizes [1], so the water droplet behavior will be different in both cases. Various numerical studies related to the atmospheric icing on structures can be found in literature. The first attempts were made from late 1970's, where researchers, such as Ackley and Templeton [5], Lozowski and Oleskiw [6]-[8], McComber et al. [9] [10] and Smith and Barker [11], concentrated on understanding the physical ice accretion processes and developing numerical models to predict the severity of icing on structures. Later Makkonen [12] [13], Finstad et al. [14], Shin et al. [15]-[17], Skelton et al. [18] \& Virk et al. [19]-[21] worked on numerical modelling of the atmospheric ice accretion on different structures.

This paper describes the study of atmospheric ice accretion on a non-rotating vertical circular cylindrical rod, having the dimensions as per ISO 12494 standard (diameter $=30 \mathrm{~mm}$, length $=500 \mathrm{~mm}$ ), at both dry and wet ice conditions. The main purpose of this work is to understand the ice growth along circular cylindrical objects such as power network cables \& tower masts, etc., installed in the cold regions. To make the problem easier and to understand the basics of ice accretion, a simple vertical circular cylindrical object is assumed in this study. The accreted ice shapes obtained from the numerical analyses are validated with the experimental results obtained from CES, Japan.

\section{Numerical/Experimental Setup}

3D CFD based numerical analyses were carried out using a finite element based Navier Stoke equation solver "FENSAP-ICE" from Numerical Technologies International NTI [22]. Hybrid numerical grid was used, where as to accurately determine the boundary layer characteristics (shear stresses and heat fluxes), a $\mathrm{y}^{+}$value less than 1 was used near the wall. Two equations k-epsilon turbulence model was used as a compromise between acceptable computational cost and the required accuracy in simulating the turbulent flow. Two phase flow (air \& water) was solved using Eulerian-Eulerian approach in FENSAP-ICE, where super cooled water droplets were assumed to be spherical. The main advantage of using Eulerian-Eulerian approach is that, the same mesh can be used for multiphase flow calculations and ice geometry.

The Eulerian two phase fluid model consists of the Navier-Stokes equation, augmented by the water droplets continuity and momentum equation. The water droplet drag coefficient is based on the empirical correlation for the flow around the spherical droplets described by Clift et al. [23]. Surface thermodynamic and icing rate are calculated by using the mass and energy conservation equations, considering the heat fluxes due to convective cooling, evaporative cooling, heat of fusion, viscous heating, kinetic heating and solar radiation. ALE (Arbitrary Langrangian Eulerian) formulation was used for the mesh displacement due to ice accretion in time. This approach adds the grid speed terms to the Navier-Stokes equations to account for the mesh velocity [24]. The numerical simulations were carried out at the operating and geometric conditions specified in Table 1.

The experimentation was performed at the Cryospheric Environmental Simulator 'CES' in Shinjo, Japan. The test section dimensions and the icing tunnel facility can be seen in Figure 1.

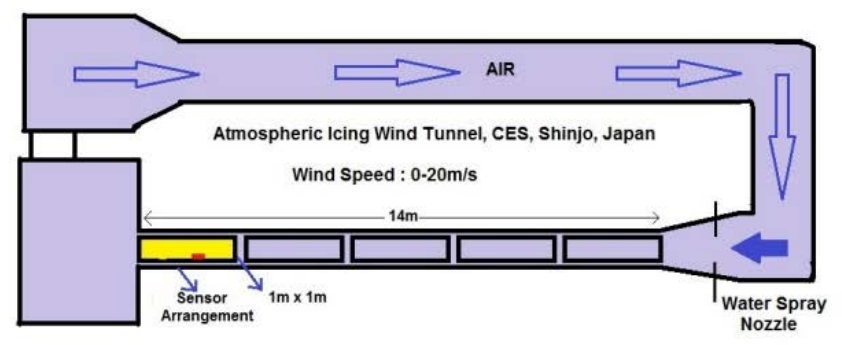

(a)

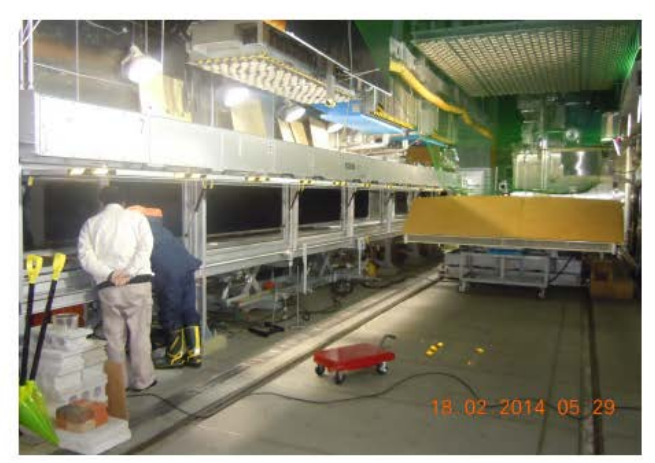

(b)

Figure 1. Cryospheric environmental simulator test facility used for this study. (a) CES icing wind tunnel; (b) CES icing wind tunnel test section. 
Table 1. Operating conditions used for the numerical simulations for this study.

\begin{tabular}{cc}
\hline Free stream wind velocity $[\mathrm{m} / \mathrm{s}]$ & 10 \\
Droplet size, $\mathrm{MVD}[\mu \mathrm{m}]$ & 22 \\
Liquid water content, $\mathrm{LWC}\left[\mathrm{g} / \mathrm{m}^{3}\right]$ & 0.5 \\
Atmospheric air temperatures $\left[{ }^{\circ} \mathrm{C}\right]$ & $-2,-15$ \\
Simulation time $[$ minutes $]$ & 180 \\
Cylinder diameter $[\mathrm{mm}]$ & 30 \\
Cylinder length $[\mathrm{mm}]$ & 500 \\
\hline
\end{tabular}

\section{Results \& Discussion}

The focus of this study has been on understanding the ice growth on circular cylindrical cross sections. The results obtained from numerical simulations (ice profile shape) were also compared with the experimental results, obtained from experimental expedition of atmospheric icing research team of Narvik University College (NUC) conducted at cryospheric environment simulator (CES), Japan.

\subsection{Airflow \& Droplet Behavior}

Numerical analyses of the airflow behavior showed a change in the velocity and pressure distribution along windward and leeward sides of the cylinder. Low flow separations zones were observed at downstream (leeward) side. Such flow behavior affects the aerodynamics and convective heat transfer during the ice accretion process. Two phase flow (air \& water) was simulated using Eulerian-Eulerian approach, where water droplets, MVD = $22 \mu \mathrm{m}$, were assumed to be spherical. Numerical analyses also showed that most droplets collide at the windward side of the cross sections. Such behavior of droplet collision location affects the surface heat transfer due to latent heat of fusion and droplet kinetic energy during the ice accretion process. Figure 2 shows the velocity vectors and droplet collision efficiency distribution along cylindrical surface.

\subsection{Atmospheric Ice Accretion}

To study the rate and shape of atmospheric ice accretion, analyses were carried out for $t=180$ minutes, where each time step was $\Delta t=0.0001 \mathrm{sec}$. Figure 3 shows the atmospheric ice growth on each cross section. Numerical results of icing rate and location is found to be in reasonably good agreement with the experimental results. The rate of ice accretion is found to be high at the locations of high droplet collision efficiency. Ice accretion is mainly occurred at windward side, whereas very little ice accretion is observed at the leeward side.

To further study and understanding of the ice growth, detailed analyses were carried out, for both dry and wet ice conditions at $\mathrm{t}=60$ minutes. Ice growth and thickness were studied along circular cylinder cross sections. Air flow \& droplet collision considerably affect the resultant ice accretion, as it determines the heat fluxes and possible locations and frequency of ice accretion. Results showed that most of the droplets only hits at front side of the cylindrical cross sections. Due to water droplet collision with the surface, the latent heat is released by the droplets that are transferred to the surface, which increases the surface temperature at the point of droplet collision. Heat balance during the ice accretion process is mainly the combination of the aerodynamic heating from the compression of the flow, the kinetic energy of the droplet impact, the latent heat released by the droplet freezing and the heat loss in warming the super-cooled droplets to $0^{\circ} \mathrm{C}$. Figure 4 shows the ice growth and accreted ice thickness distribution along circular cross section at dry and wet ice conditions along vertical and longitudinal axis of cylinder for $\mathrm{t}=60$ minutes.

Results show a considerable change in growth with the variation of atmospheric temperatures. At $\mathrm{T}=-15^{\circ} \mathrm{C}$ (dry ice conditions), higher accreted ice thickness and growth was observed as compared to $\mathrm{T}=-2^{\circ} \mathrm{C}$ (wet ice conditions). This is mainly due to higher droplet freezing fraction at $\mathrm{T}=-15^{\circ} \mathrm{C}$. Moreover results show that more streamlined ice shapes were observed at $\mathrm{T}=-15^{\circ} \mathrm{C}$, meanwhile at $\mathrm{T}=-2^{\circ} \mathrm{C}$ more irregular and horny shapes of accreted ice were observed, which can possibly lead to an increase in aerodynamic drag and resultant dynamics instabilities in structural behavior. 


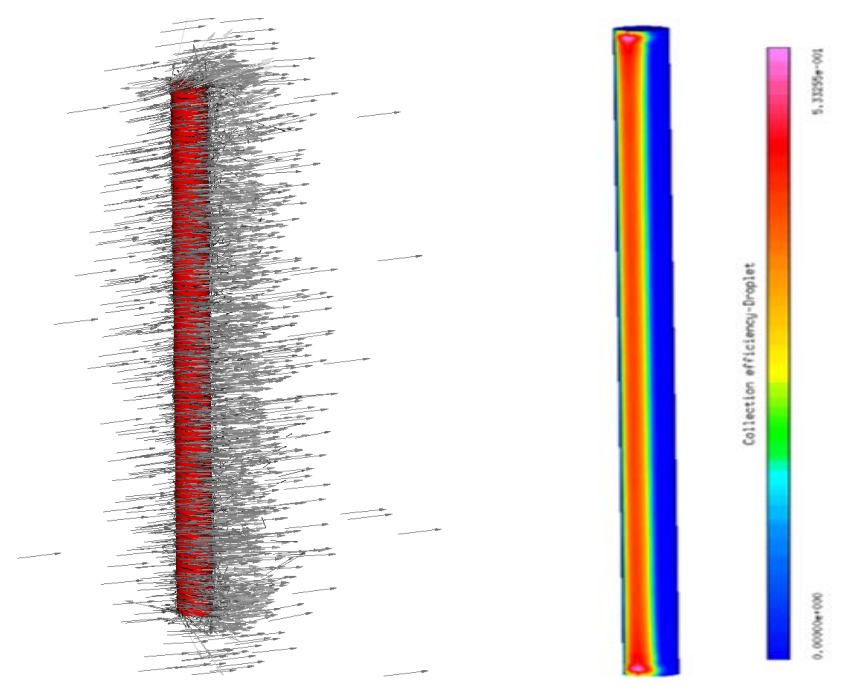

Figure 2. Velocity vectors \& droplet collision efficiency along circular cylinder.
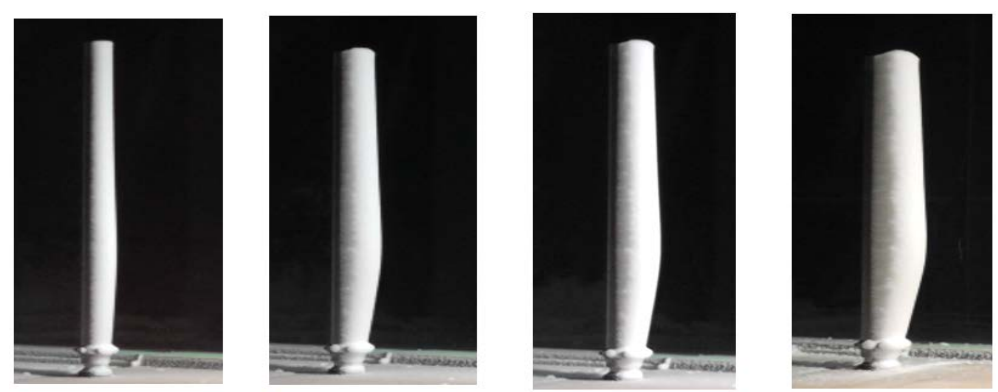

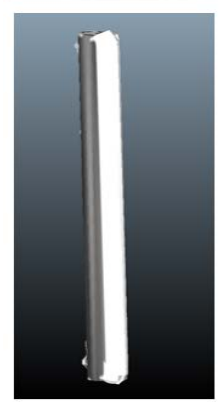

$(\mathrm{t}=60 \mathrm{~min})$

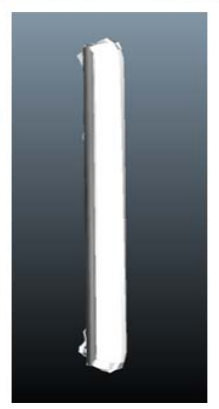

$(\mathrm{t}=90 \mathrm{~min})$

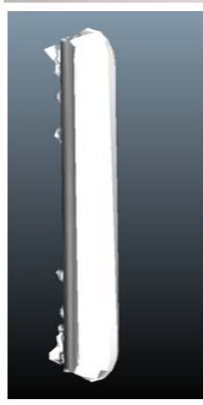

$(\mathrm{t}=120 \mathrm{~min})$

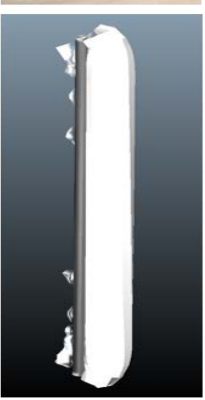

$(\mathrm{t}=180 \mathrm{~min})$

Figure 3. Ice growth (experimental \& numerical) along vertical circular cylinder, at $\mathrm{T}=-15^{\circ} \mathrm{C}$.

\section{Conclusions}

This research study provided the useful information and insight of the ice accretion on a 3D non rotating circular cylinder. This information can provide a useful base for further numerical investigation of atmospheric ice accretion on circular power network cables, installed in the cold regions. Analysis shows that in case of circular cylinder streamlined airflow behavior was observed with the very low flow separation zone at leeward side, super cooled droplet mainly collided with the windward side, which resulted in ice accretion mainly in windward side. Very little ice accretion was observed at the leeward side, which highlights the possibility of structural dynamics instabilities due to irregular distribution on accreted ice along cylindrical surface. Results show a significant change in ice growth along circular cylinder surface with the change in operating temperatures. At dry ice conditions $\left(\mathrm{T}=-15^{\circ} \mathrm{C}\right)$, more streamlined ice shapes were observed as compared to wet ice conditions $(\mathrm{T}=$ $\left.-2^{\circ} \mathrm{C}\right)$. 

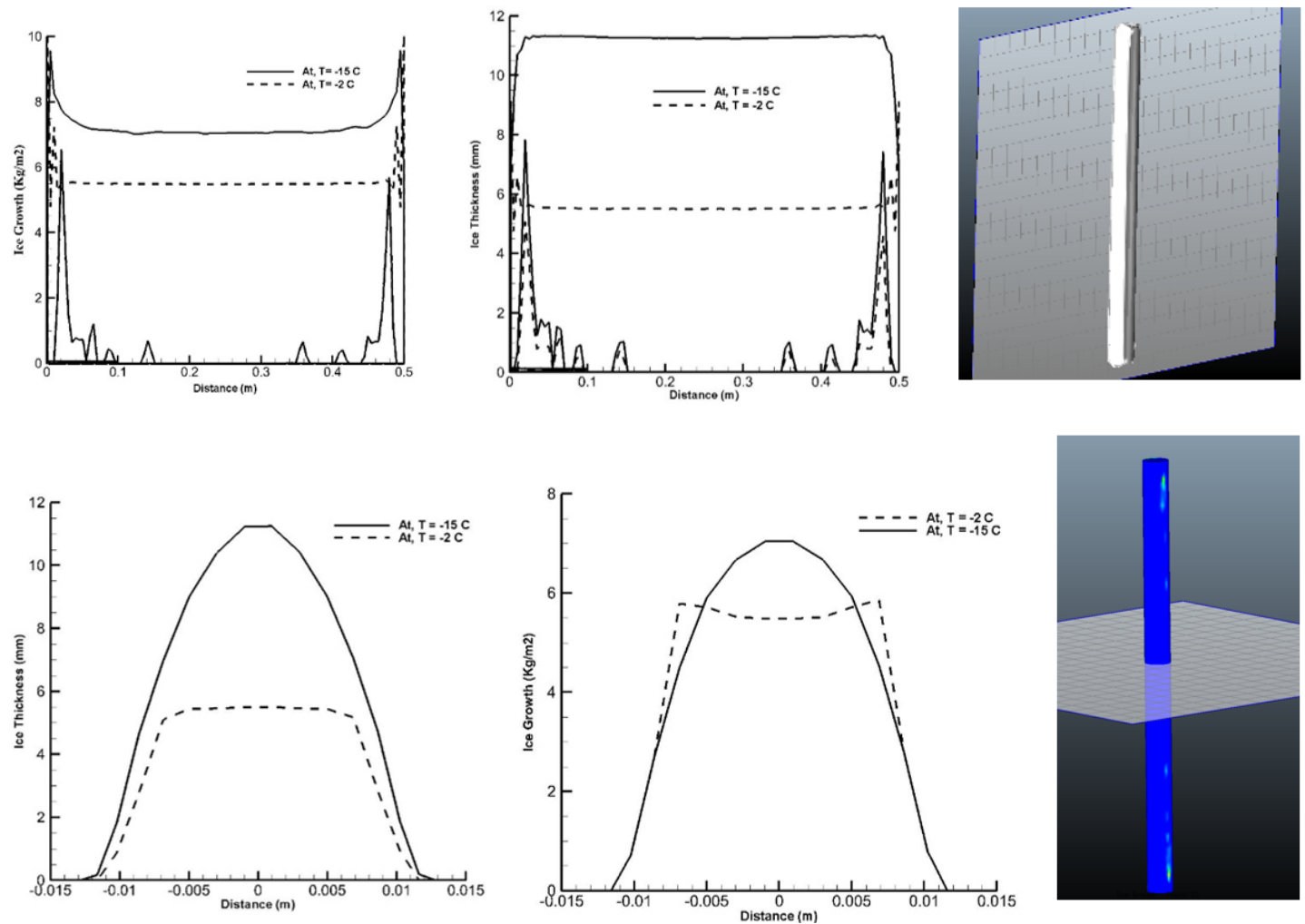

Figure 4. Atmospheric ice accretion along circular cylinder at different operating temperatures for $\mathrm{t}=$ 60 minutes.

\section{Acknowledgements}

The work reported in this research paper was carried out by Atmospheric Icing Research Team at Industrial Engineering Department of Narvik University College and was funded by Research Council of Norway, project no. 195153 (ColdTech RT3 and RT5) and Norwegian centre for international cooperation in education, project number- HNP-2014/10023.

\section{References}

[1] Fu, P., Farzaneh, M. and Bouchard, G. (2006) Two Dimensional Modelling of the Ice Accretion Process on Transmission line Wires and Conductors. Cold Region Science \& Technology, 46, 132-146. http://dx.doi.org/10.1016/j.coldregions.2006.06.004

[2] Llinca, A., Llinca, F. and Ignat, L. (1996) Numerical Study of Iced Conductor Aerodynamics. In: 7th International Workshop on Atmospheric Icing on Structures.

[3] Drage, M.A. (2005) Atmospheric Icing and Meteorological Variables_Full Scale Experiment and Testing of Models. Department of Geophysics, University of Bergen, Bergen, Norway.

[4] Wagner, T., PEil, U. and Borri, C. (2009) Numerical Investigation of Conductor Bundle Icing. EACWE 5, Florence, Italy.

[5] Ackely, S.F. and Templeton, M.K. (1979) Computer Modelling of Atmopsheric Ice Accretion. USA Cold Region Research and Engineering Laboratory.

[6] Lozowski, E.P., Stallabrass, J.R. and Hearty, F.P. (1983) The Icing of an Unheated, Non-Rotating Cylinder, Part I: A Simulation Model. Journal of Climate and Applied Meteorology, 22, 2053-2062. http://dx.doi.org/10.1175/1520-0450(1983)022<2053:TIOAUN>2.0.CO;2

[7] Lozowski, E.P. and Oleskiw, M.M. (1983) Computer Modelling of Time Dependant Rime Icing in the Atmosphere. USA Cold Regions Research and Engineering Laboratory.

[8] Lozowski, E.P., Finstad, K.J. and Gates, E.M. (1985) Comments on Calculation of the Impingement of Cloud Droplets on a Cylinder by Finite Element Method. Journal of Atmospheric Science, 42, 306-307. 
http://dx.doi.org/10.1175/1520-0469(1985)042<0306:COOTIO >2.0.CO;2

[9] McComber, P. (1983) Numerical Simulation of Ice Accretion on Cables. In: First International Workshop on Atmospheric Icing on Structures. Haniver, Hampshire.

[10] McComber, P., Martin, R. and Morin, G. (1983) Estimation of Combined Ice and Wind Loads on Overhead Transmission Lines. In: First International Workshop on Atmospheric Icing on Structures, Hanover, Hampshire.

[11] Smoth, B.W. and Barker, C.P. (1983) Icing of Cables. In: First International Workshop on Atmospheric Icing on Structures, Hanover, Hampshire.

[12] Makkonen, L. (2000) Models for the Growth of Rime, Glaze, Icicles and Wet Snow on Structures. Philosiphical Transactions of the Royal Society A, 358, 2913-2939. http://dx.doi.org/10.1098/rsta.2000.0690

[13] Makkonen, L., Laakso, T. and Marjaniemi, M. (2001) Modelling and Prevention of Ice Accretion on Wind Turbines. Wind Engineering, 25, 3-21. http://dx.doi.org/10.1260/0309524011495791

[14] Finstad, K.J., Lozowski, E.P. and Gates, E.M. (1988) A Computational Investigation of Water Droplet Trajectories. Journal of Atmospheric and Oceanic Technologies, 5, 160-170. http://dx.doi.org/10.1175/1520-0426(1988)005<0160:ACIOWD>2.0.CO;2

[15] Shin, J. (1994) Prediction of Ice Shapes and Their Effect on Airfoil Drag. Journal of Aircraft, 31, $263-270$. http://dx.doi.org/10.2514/3.46483

[16] Boutanios, Z. (1999) An Eulerian 3D Analysis of Water Droplets Impingement on a Convair-580 Nose and Cockpit Geometry. In: Department of Mechanical Engineering, Concordia University, Montreal, Canada.

[17] Shin, J. and Bind, T.H. (1992) Experimental and Computational Ice Shapes and Resulting Drag Increase for a NACA 0012 Airfoil. NASA Technical Memorandum 105743.

[18] Skelton, P.L.I. and Poots, G. (1991) Snow Accretion on Overhead Line Conductors of Finite Torsional Stiffness. Cold Region Science and Technology, 19, 301-316. http://dx.doi.org/10.1016/0165-232X(91)90045-I

[19] Virk, M. (2011) Numerical Study of Atmospheric Ice Accretion on Various Geometric Cross Sections. Wind Engineering, 35, 607-614.

[20] Virk, M.S., et al. (2010) Effect of Atmospheric Temperature and Droplet Size Variation on Ice Accretion of Wind Turbine Blades. Journal of Wind Engineering and Industrial Aerodynamics, 98, 724-729. http://dx.doi.org/10.1016/j.jweia.2010.06.007

[21] Virk, M.S. (2013) Atmospheric Ice Accretion on Circular Overhead Powerline Conductors Installed in Tandem Arrangement. International Journal of Computational Multiphase Flow, 5, 73-81. http://dx.doi.org/10.1260/1757-482X.5.1.73

[22] http://www.newmerical.com/index.php/products/fensap-ice-cfd-software/

[23] Clift, R., Grace, J.R. and Weber, M.E. (1978) Bubbles, Drops and Particles. Academic Press, New York.

[24] Manual, N.S.U. 2010, NTI. 